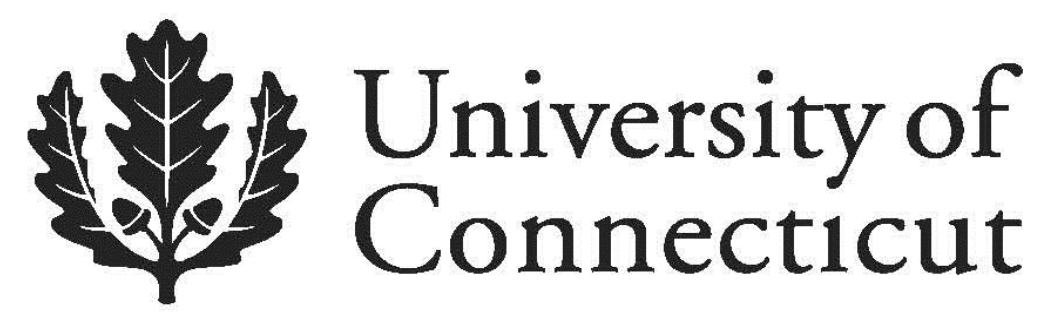

Department of Economics Working Paper Series

The impact of the correlation between health expenditure and survival probability on the demand for insurance

Kai Zhao

University of Connecticut

Working Paper 2014-37

December 2014

365 Fairfield Way, Unit 1063

Storrs, CT 06269-1063

Phone: (860) 486-3022

Fax: (860) 486-4463

http://www.econ.uconn.edu/

This working paper is indexed on RePEc, http://repec.org 


\title{
The impact of the correlation between health expenditure and survival probability on the demand for insurance*
}

\author{
Kai Zhao ${ }^{\dagger}$ \\ University of Connecticut
}

December 13, 2014

\begin{abstract}
This paper studies the effects of health shocks on the demand for health insurance and annuities, along with precautionary saving in a dynamic life-cycle model. I argue that when the health shock can simultaneously increase health expenses and reduce longevity, rational agents would neither fully insure their uncertain health expenses nor fully annuitize their wealth because the correlation between health expenses and longevity provides a self insurance channel for both uncertainties. That is, when the agent is hit by a health shock (which simultaneously increases health expenses and reduces longevity), she can use the resources originally saved for consumption in the reduced period of life to pay for the increased health expenses. Since the two uncertainties partially offset each other, the precautionary saving generated in the model should be smaller than in a standard model without the correlation between health expenses and longevity. In a quantitative life-cycle model calibrated using the Medical Expenditure Panel Survey dataset, I find that the health expenses are highly correlated with the survival probabilities, and this correlation significantly reduces the demand for actuarially-fair health insurance, while its impact on the demand for annuities and precautionary saving is relatively small.
\end{abstract}

Keywords: Health Insurance, Annuities, Precautionary Saving.

JEL Classifications:

${ }^{*}$ I would like to thank the editor Ayse Imrohoroglu, the associate editor, and the two anonymous referees for their helpful comments and suggestions. I also would like to thank Daniel Brou, Hugh Cassidy, Betsy Caucutt, Jim Davies, and Karen Kopecky for their useful comments. All errors are mine. This paper was originally circulated under the title "Health Insurance, Annuities, and Precautionary Saving".

${ }^{\dagger}$ Department of Economics, The University of Connecticut, Storrs, CT, USA (email: kai.zhao@uconn.edu). 


\section{Introduction}

It is well known that health expenses in developed countries have risen dramatically over the last several decades and are projected to continue rising in the near future. For instance, the US aggregate health expenses rose from 5.2\% of GDP in 1960 to $16 \%$ of GDP in 2007, and are projected to be $25 \%$ in 2025 and $37 \%$ in $2050 .{ }^{1}$ Importantly, health expenses are extremely volatile and a significant portion of these expenses are not insured (out-of-pocket expenses). Meanwhile, a large cohort of baby boomers will be retiring in the next decade. Hence, it is important to understand how health shocks affect retirees' lifetime financial planning.

In this paper, I develop a dynamic life-cycle model with health shocks and use it to study the effects of health shocks on the demand for health insurance and annuities, and precautionary saving. In particular, I focus on health shocks that simultaneously increase health expenses and reduce longevity, and how they affect retirees' lifetime financial planning decisions.

Many types of health shocks have simultaneous effects on health expenses and longevity. For instance, entering into long term care not only significantly increases health expenses, but also reduces survival probabilities to the future (Sinclair and Smetters, 2004, Kopecky and Koreshkova, 2009, etc.) Hurd, McFadden, and Merrill (2001) found that a variety of health conditions (e.g., cancer, heart disease) can reduce survival probabilities. Similar results are found for the general concept of a health shock, a health status change. De Nardi, French, and Jones (2010) documented in the AHEAD data that conditional on permanent income, gender, and age, people in good health status spend around $50 \%$ less on health care annually than those in bad health status, but they expect to live about 3 years longer than those in bad health.

I argue that when health shocks can simultaneously increase health expenses and reduce longevity, several interesting results can be obtained. First, utility-maximizing agents would neither fully insure their uncertain health expenses nor fully annuitize their wealth, even when these insurance policies are actuarially-fair and there is no bequest motive. Second, when the insurance markets for uncertain health expenses and uncertain longevity are missing, the precautionary saving generated by these uncertainties may be smaller than in a model without the correlation between health expenses and longevity.

The intuition behind these results is simple. The simultaneous effect of health shocks on health expenses and longevity provides agents with a self insurance channel for both uncertain health expenses and uncertain longevity. When the agent is hit by a health shock (which simultaneously increases health expenses and reduces longevity), she can use the resources originally saved for consumption in the reduced period of life to pay for the increased health expenses. As

\footnotetext{
${ }^{1}$ The 1960 and 2007 numbers are from OECD Health Data 2009. The projected numbers are from the Congressional Budget Office.
} 
a result, agents would neither fully insure their health expenses nor fully annuitize their wealth. Similarly, when the insurance markets for uncertain health expenses and uncertain longevity are missing, since the two uncertainties partially offset each other through the correlation between them, the precautionary saving generated in the model would be smaller than in a model without the correlation between health expenses and longevity.

To assess the quantitative importance of the above described results, I develop a quantitative dynamic life cycle model with uncertain health expenses and uncertain longevity, and calibrate the correlation between the two uncertainties using the Medical Expenditure Panel Survey (MEPS) dataset. I find that current health expenses are highly correlated with the conditional survival probabilities to the next period. Then, I run computational experiments in the calibrated model to quantify the impact of the correlation between health expenses and survival probabilities. I find that its impact on the demand for health insurance is quantitatively large, while its impact on the demand for annuities and precautionary saving is relatively small.

Some existing studies have also implicitly captured the correlation between health expenses and longevity. For instance, De Nardi, French, and Jones (2010) captured the correlation between health expenses and survival probabilities via including health status as a state variable in their model. Kopecky and Koreshkova (2009) partially captured the correlation via modelling a nursing home shock. However, these studies usually do not model the decisions to buy health insurance and annuities, and thus have not explored the implications of this correlation for the demand for health insurance and annuities, which is the main goal of this paper. In addition, I assume that the survival probability is directly conditioned on the current health expense, and measure the magnitude of the correlation between health expenses and survival probabilities from the MEPS dataset.

This paper also contributes to the literature that aims to understand why households do not buy more private health insurance and annuitize their wealth. ${ }^{2}$ I find that the correlation between health expenses and survival probabilities is an important reason why many individuals do not buy more private health insurance, but it cannot explain the non-annuitization puzzle.

This paper is related to Sinclair and Smetters (2004) who have also studied the implications from the simultaneous effect of health shocks on health expenses and longevity. In a quantitative OLG model, they show that the simultaneous effect of health shocks on health expenses and longevity reduces the demand for annuities via numerical simulations. In this paper, I show that the correlation between health expenses and survival probabilities also reduces the demand for

\footnotetext{
${ }^{2}$ For the literature on health insurance, see Pauly (1990), Cutler and Gruber (1996a, 1996b), Brown and Finkelstein (2007, 2008), Gruber (2008), Lockwood (2013), Zhao (2014), etc. For the literature on annuitizatoin, please see Yaari (1965), Kotlikoff and Spivak (1981), Sinclair and Smetters (2004), Yogo (2009), Lockwood (2011), Pashchenko (2013), etc.
} 
health insurance, and this effect is quantitatively more important than the effect on the demand for annuities. In addition, I provide new implications for precautionary saving, and show that the impact from the correlation between health expenses and longevity may be different across the income distribution.

This paper is also related to a recent growing literature that uses quantitative dynamic models to study the impact of uncertain health expenses on precautionary saving. ${ }^{3}$ In this paper, I argue that the correlation between health expenses and survival probabilities provides agents a self insurance channel, and thus may be important for understanding the impact of uncertain health expenses on precautionary saving.

The rest of the paper is organized as follows. In section 2, I present a simple example to illustrate the intuition. In section 3, I study an analytical model and derive some theoretical results. I develop the full quantitative dynamic life cycle model in section 4 and present the main quantitative results in section 5 . I conclude in section 6 .

\section{A Simple Model}

In this section, I present a simple model to illustrate the intuition behind the main findings of this paper. Here I only look at the problem after retirement. Assume that an agent with endowment $W$ faces the following two-period expected utility maximization problem,

$$
\max _{C_{1}(h), C_{2}(h)} E\left[U\left(C_{1}(h)\right)+S(h) U\left(C_{2}(h)\right)\right]
$$

subject to

$$
\begin{gathered}
W-M(h)-C_{1}(h)=C_{2}(h), \forall h, \\
C_{1}(h) \geq 0 \text { and } C_{2}(h) \geq 0, \forall h
\end{gathered}
$$

Here $U(C)$ represents the utility flow derived from consumption $C, M$ is the health expense, and $S$ is the survival probability to period 2. The agent receives a health shock, $h$, at the beginning of period 1 . When it is a bad shock, i.e., $h=h_{b}$, the agent needs to pay health expenses $M\left(h_{b}\right)=\frac{W}{2}$, and she will not survive to period 2 for sure, i.e., $S\left(h_{b}\right)=0$. When it is a good shock, the agent needs to pay no health expense, i.e., $M\left(h_{g}\right)=0$, and she will survive to the second period for sure, i.e., $S\left(h_{g}\right)=1$. For simplicity, the discount factor and the gross interest rate are both equal to one.

Assuming that there are neither health insurance nor annuities available, the agent's optimal decision can be easily derived: $C_{1}\left(h_{g}\right)=C_{1}\left(h_{b}\right)=\frac{W}{2}, C_{2}\left(h_{g}\right)=\frac{W}{2}$. Note that the agent faces

\footnotetext{
${ }^{3}$ Hubbard, Skinner, and Zeldes (1995), De Nardi, French, and Jones (2010), Kopecky and Koreshkova (2009), etc.
} 
both uncertain health expenses and uncertain longevity in this environment, but she is able to achieve perfect consumption smoothing over different states and time periods, even without any health insurance or annuities. The intuition behind this result is clear; the simultaneous effect of the health shock on longevity and health expenses provides the agent with a self insurance channel for both uncertain longevity and uncertain health expenses. When the agent is hit by a bad shock, she uses the resources originally saved for consumption in period 2 to pay the increased health expenses.

\section{The Analytical Model}

There exist ex ante homogeneous agents of measure one. Again, here I only look at the problem after retirement. Each agent is initially endowed with asset $W$. At the beginning of time, she is hit by a health shock, $h$, which will determine her lifetime health expenses, $M(h)$, and longevity, $T(h)$. For simplicity, it is assumed that both the discount factor and the gross interest rate are equal to one. To have a meaningful problem, I also assume that the expected health expenses are less than the initial endowment, i.e., $E[M(h)]<W$. Agents face the following expected utility maximizing problem.

$$
\max _{\{C(t, h)\}_{0}^{T(h)}} E\left[\int_{0}^{T(h)} U(C(t, h)) d t\right]
$$

subject to

$$
\begin{gathered}
W-M(h)=\int_{0}^{T(h)} C(t, h), \forall h . \\
C(t, h) \geq 0, \forall h, t,
\end{gathered}
$$

Here $U($.$) satisfies the following conditions: U^{\prime}>0, U^{\prime \prime}<0, U^{\prime \prime \prime}>0$, and the Inada conditions. $C(t, h)$ represents the consumption at time $t$, conditional on the health shock, $h$, which has the following properties: $h=h_{g}$ (good shock) with a probability of $1-P$, and $h=h_{b}$ (bad shock) with a probability of $P$. The lifetime health expenses and the longevity are determined by the health shock in the following way, $M\left(h_{g}\right)=0, M\left(h_{b}\right)=M$, and $T\left(h_{g}\right)=T$, $T\left(h_{b}\right)=\delta T$, where $0<\delta<1$.

Since both the discount factor and the gross interest rate are equal to one, it is obvious that rational agents will choose a flat consumption path after the health shock. That is, $C(t, h)=$ $C\left(t^{\prime}, h\right)$, for any $t, t^{\prime} \in[0, T(h)]$. Using $C(h)$ to represent the constant consumption per period, the above utility maximizing problem is simplified to the following problem,

$$
\max _{C(h)} E[T(h) U(C(h))]
$$


subject to

$$
\begin{gathered}
W-M(h)=T(h) C(h), \forall h \\
C(h) \geq 0, \forall h .
\end{gathered}
$$

Assuming that neither annuities nor health insurance are available, the optimal solution for the above problem can be easily obtained. That is, $C^{*}\left(h_{g}\right)=\frac{W}{T}$ and $C^{*}\left(h_{b}\right)=\frac{W-M}{\delta T}$. As can be seen, health insurance or annuities before the health shock is revealed can be welfare-improving as long as the following condition holds,

$$
C^{*}\left(h_{g}\right)=\frac{W}{T} \neq \frac{W-M}{\delta T}=C^{*}\left(h_{b}\right)
$$

thus,

$$
M \neq W(1-\delta)
$$

\subsection{Health Insurance}

Now I consider agents' demand for health insurance in this model. Assume that the annuity market is closed, but agents have access to actuarially-fair health insurance. That is, the price of health insurance with a coinsurance rate of $I$ is $q_{I}=P I M$. Agents maximize their expected lifetime utility by choosing the optimal coinsurance rate, $I^{*}$. That is, they face the following expected utility-maximizing problem,

$$
\max _{C(h), I} E[T(h) U(C(h))]
$$

subject to

$$
\begin{gathered}
W-M(h)-P I M+M(h) I=T(h) C(h), \forall h, \\
C(h) \geq 0, \forall h, \text { and } I \geq 0 .
\end{gathered}
$$

Let us study this problem in two different scenarios.

$(1) M \leq W(1-\delta)$. As shown in equations (7) and (8), even without any health insurance, agents already have a higher consumption per period after a bad health shock than after a good shock. Therefore, in this scenario, agents do not need any health insurance, i.e., $I^{*}=0$ (corner solution). The intuition behind this result is simple. If the health expenses (i.e., $M$ ) are not larger than the resources freed up from a reduction in longevity (i.e., $W(1-\delta)$ ), health insurance is not needed, as the self insurance channel itself is enough to insure against the risk.

$(2) M>W(1-\delta)$. In this scenario, there exists an interior solution for $I$. After substituting the budget constraint into the objective function, the following First Order Condition (FOC) 
can be obtained,

$$
-(1-P) T U^{\prime}\left(\frac{W-P I M}{T}\right) \frac{P M}{T}-P \delta T U^{\prime}\left(\frac{W-M-P I M+I M}{\delta T}\right)(M-P M) \frac{1}{\delta T}=0
$$

Rearranging the above equation and solving for $I$,

$$
I^{*}=\frac{1-\frac{W}{M}(1-\delta)}{1-P(1-\delta)}
$$

The above equation describes the optimal solution for $I^{*}$. From this equation, the following propositions can be obtained,

Proposition 1: (1) The optimal health coinsurance rate, $I^{*}$, is less than 1 . In other words, agents do not choose to fully insure their health expense risk. (2) The optimal health coinsurance rate, $I^{*}$, decreases as the reduction in life expectancy increases, i.e., $\frac{\partial I^{*}}{\partial \delta}<0, I^{*}$ increases as the probability of getting a bad shock increases, i.e., $\frac{\partial I^{*}}{\partial P}>0$, and $I^{*}$ decreases as the endowment increases, $\frac{\partial I^{*}}{\partial W}<0$.

Proof: As for statement (1), since the expected health expense is less than the initial endowment, the following inequation holds, $E[M(h)]=P M<W$. Rearranging and multiplying both sides of this inequation by $(1-\delta)$, I obtain $P(1-\delta)<\frac{W}{M}(1-\delta)$. As a result, $1-\frac{W}{M}(1-\delta)<$ $1-P(1-\delta)$, and thus $I^{*}=\frac{1-\frac{W}{M}(1-\delta)}{1-P(1-\delta)}<1$. Statement $(2)$ can be simply obtained by taking the first order derivative of equation (12) with respect to $\delta, P$, and $W$, respectively.

\section{$3.2 \quad$ Annuities}

Now I consider agents' demand for annuities in this model. Assume that the health insurance market is closed, but agents have access to actuarially-fair annuities. That is, the price of an annuity policy that pays $A$ per period while alive is, $q_{A}=P \delta T A+(1-P) T A$. Note that rational agents never spend more than $W-M$ on annuities, otherwise they will not have resources for consumption after a bad health shock. That is, they never choose an annuity level $A>\frac{W-M}{P \delta T+(1-P) T}$. Therefore, the optimal annuity level, $A^{*}$, solves the following problem,

$$
\max _{A} E[T(h) U(C(h))]
$$

subject to

$$
\begin{gathered}
W-M(h)-(P \delta T A+(1-P) T A)+T(h) A=T(h) C(h), \forall h \\
C(h) \geq 0, \forall h, \text { and } A \geq 0 .
\end{gathered}
$$

Again, I analyze the problem in two cases. 
(1) $M \geq W(1-\delta)$. In this case, even without purchasing any annuity, the agent would already have a higher consumption per period when she happens to live longer than expected. Therefore, agents do not need any annuity, i.e., $A^{*}=0$. The intuition behind this result is simple. If the health expense saved is larger than the resources needed for the extra years of life, no annuity is needed.

$(2) M<W(1-\delta)$. In this case, agents need annuities to insure against the risk of outliving their resources (interior solution). After substituting the budget constraints into the objective function, the following FOC can be obtained,

$$
\begin{gathered}
(1-P) T U^{\prime}\left(\frac{W}{T}-(P \delta A+(1-P) A)+A\right)[1-(P \delta+(1-P))]+ \\
P \delta T U^{\prime}\left(\frac{W-M}{\delta T}-\left(P A+\frac{(1-P) A}{\delta}\right)+A\right)\left[1-\left(P+\frac{(1-P)}{\delta}\right)\right]=0
\end{gathered}
$$

Rearranging the above equation and solving for $\mathrm{A}$,

$$
A^{*}=\frac{W-\frac{M}{1-\delta}}{P \delta T+(1-P) T}
$$

The above equation describes the optimal annuity level, and the price of this annuity policy is,

$$
q_{A}^{*}=(P \delta T+(1-P) T) A^{*}=W-\frac{M}{(1-\delta)}
$$

As can be seen, the annuitized wealth (measured by $q_{A}^{*}$ ) is less than the total wealth available after the health shock ( $W$ or $W-M)$. In other words, agents do not fully annuitize their wealth. I summarize the main properties of the optimal annuitization decision in the following proposition.

Proposition 2: (1) Agents do not fully annuitize their wealth, i.e., $q_{A}^{*}<W-M$ or $W$. (2) The annuitized wealth (measured by $q_{A}^{*}$ ) increases as the initial wealth increases, i.e., $\frac{\partial q_{A}^{*}}{\partial W}>0$. (3) The annuitized wealth decreases as the health expenses increase, i.e., $\frac{\partial q_{A}^{*}}{\partial M}<0$. (4) The annuitized wealth increases as the reduction in life expectancy increases, i.e., $\frac{\partial q_{A}^{*}}{\partial(1-\delta)}>0$.

Proof: Statement (1) is from the assumption $0<\delta<1$. Statements (2)-(4) can be easily obtained by taking the first order derivative of equation (16) with respect to $W, M$, and $1-\delta$, respectively.

It may be also interesting to look at another measure of annuitization, the fraction of wealth that is annuitized, which can be measured by $\frac{q_{A}^{*}}{W}=1-\frac{M}{(1-\delta) W}$. By taking the first order derivative of $\frac{q_{A}^{*}}{W}$ with respect to $W, M$, and $1-\delta$, respectively, it is easy to see that statements (2)-(4) in proposition 2 would still hold if $\frac{q_{A}^{*}}{W}$ is used as the measure of annuitization instead of $q_{A}^{*} \cdot{ }^{4}$

\footnotetext{
${ }^{4}$ Note that the same result is obtained if $\frac{q_{A}^{*}}{W-M}$ is used instead of $\frac{q_{A}^{*}}{W}$.
} 
Based on the analysis in the previous sections, it is easy to see the results when both health insurance and annuities are available in the model. ${ }^{5}$ That is, agents with endowment $W>\frac{M}{1-\delta}$, only need annuities $\left(A^{*}=\frac{W-\frac{M}{1-\delta}}{P \delta T+(1-P) T}\right)$, while agents with endowment $W \leq \frac{M}{1-\delta}$, only need health insurance $\left(I^{*}=\frac{1-\frac{W}{M}(1-\delta)}{1-P(1-\delta)}\right) .^{6}$

The intuition behind the results in the model with both health insurance and annuities markets is simple. Since the relatively rich (agents with $W>\frac{M}{1-\delta}$ ) tend to consume more per period than the relatively poor (agents with $W \leq \frac{M}{1-\delta}$ ), for the same reduction in longevity, the resources freed up for the relatively rich are usually more than those for the relatively poor, and thus they are more likely to be enough to compensate for the simultaneous increase in health expenses. In other words, the correlation between health expenses and longevity has differential effects across the income distribution, i.e., it provides more insurance against uncertain health expenses for the relatively rich, and more insurance against uncertain longevity for the relatively poor.

\section{The Full Quantitative Model}

The analytical model allows us to derive closed-form solutions and see the intuition behind the mechanisms. However, to understand the quantitative importance of these mechanisms, a fullblown model is needed. In the rest of the paper, I develop a 65-period overlapping-generations model with health shocks and use it to assess the quantitative importance of the mechanisms described previously.

Consider a model economy inhabited by overlapping generations of agents who can live up to 65 periods. Agents are born at age $26(j=1)$, retire at age $65(j=R=40)$ and can live up to age $90(j=T=65)$. At the beginning of life, agents are hit by a permanent productivity shock $\epsilon$ which determines their lifetime earnings. Agents receive earnings in each period before retirement, which is denoted by $w \gamma_{j} \epsilon_{i}$. Here $w$ is wage, $\gamma_{j}$ is the age-specific productivity, and $\epsilon_{i}$ is the individual-specific permanent productivity. After retirement, they live on their savings $a$ and Social Security payments $S S\left(\epsilon_{i}\right)$. Agents face two types of uncertainty over the life cycle, uncertain health expenses $m$ and uncertain longevity (modeled via conditional survival probabilities $S$ at each age). To capture the correlation between the two uncertainties, I assume

\footnotetext{
${ }^{5} \mathrm{I}$ do not present the derivation here as it is trivial.

${ }^{6} \mathrm{It}$ is worth noting that annuities and health insurance are in fact insuring against the same risk in the model, but in the opposite direction. Therefore, the optimum can also be achieved by holding both. That is, agents can always increase their holdings of both annuities and health insurance simultaneously and still achieve perfect consumption smoothing because the extra annuities and health insurance offset each other. I rule out this possibility here. In reality, this result is very unlikely to occur because there are entry costs and administrative costs in both markets.
} 
that the conditional survival probability from age $j$ to $j+1$ is a function of the health expense in age $j$, i.e., $S_{j}\left(m_{j}\right)$. Ideally, both survival probability and health expense should be modeled as functions of the health condition/status. However, as the information on the dynamics of health conditions is limited in the data, I do not specifically model health conditions here.

Assume that there exists neither health insurance nor annuity in the benchmark model. The utility-maximization problem facing an agent at age $j$ with a permanent shock $\epsilon_{i}$, health expense $m_{j}$, and savings $a_{j}$ can be simply described by the following Bellman Equation.

$$
V\left(j, a_{j}, m_{j}, \epsilon_{i}\right)=\max _{c_{j}, a_{j+1}} \frac{c_{j}^{1-\sigma}}{1-\sigma}+\beta S_{j}\left(m_{j}\right) E\left[V\left(j+1, a_{j+1}, m_{j+1}, \epsilon_{i}\right)\right]
$$

subject to

$$
\begin{gathered}
\begin{cases}a_{j+1}+c_{j}+m_{j}=w \gamma_{j} \epsilon_{i}\left(1-\tau_{s}-\tau_{m}-\tau_{w}\right)+a_{j}(1+r)+b+t r & \text { if } \quad j \leq R \\
a_{j+1}+c_{j}+\left(1-\kappa_{m}\right) m_{j}=a_{j}(1+r)+S S\left(\epsilon_{i}\right)+t r, & \text { if } \quad j>R\end{cases} \\
a \geq 0 \text { and } c \geq 0
\end{gathered}
$$

Here $V$ is the value function, $r$ is the interest rate, and $b$ is the transfer from accidental bequests, which are assumed to be equally redistributed to the working agents.

There are three government programs: Social Security, Medicare, and the welfare program. Social Security imposes a payroll tax $\tau_{s}$ on workers and provides annuity payments $S S\left(\epsilon_{i}\right)$ to retirees. The Medicare program covers a $\kappa_{m}$ fraction of health expenses for retirees and imposes a payroll tax $\tau_{m}$ on workers. The welfare program guarantees a minimum consumption floor $\underline{c}$ by providing transfer payments $t r$, which is defined as,

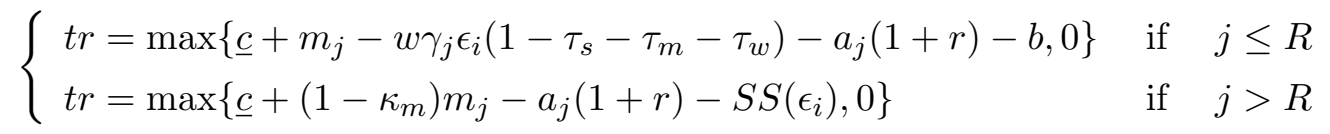

For simplicity, I assume that the prices $\{w, r\}$ are fixed; therefore, a stationary equilibrium can be simply sketched as follows. A stationary equilibrium for a given set of government parameters and prices, is a collection of value functions, individual decision rules, a distribution function, and transfer from accidental bequests, such that,

1. The value functions and individual decision rules solve the agent's utility maximization problem.

2. Social Security, Medicare, and the welfare program are self-financing.

3. The amount of transfers from bequests in each period is equal to the amount of accidental bequests in that period. 
4. The population distribution is constant over time.

Table 1: Labor Productivity Grids

\begin{tabular}{lccccc}
\hline & $\epsilon_{1}$ & $\epsilon_{2}$ & $\epsilon_{3}$ & $\epsilon_{4}$ & $\epsilon_{5}$ \\
\hline Permanent productivity & 0.23 & 0.48 & 1.00 & 2.07 & 4.27 \\
Corresponding popu. measure & 0.09 & 0.24 & 0.35 & 0.24 & 0.09 \\
\hline
\end{tabular}

Table 2: Age-specific Productivity

\begin{tabular}{lc}
\hline Age & Age-specific productivity $\gamma$ \\
\hline $26-30$ & 1 \\
$31-35$ & 1.22 \\
$36-40$ & 1.40 \\
$41-45$ & 1.50 \\
$46-50$ & 1.59 \\
$51-55$ & 1.62 \\
$56-60$ & 1.48 \\
$61-65$ & 1.24 \\
\hline \hline
\end{tabular}

Note: age $26-30$ is normalized to 1.

Table 3: Health Expenditure Grids (in 2006 \$)

\begin{tabular}{l|c|c|c|c|c}
\hline Health expense $(\$)$ & $m_{1}$ & $m_{2}$ & $m_{3}$ & $m_{4}$ & Average \\
\hline Age 66-70 & 1298 & 7293 & 21271 & 51451 & 7202 \\
Age 71-80 & 1762 & 9120 & 26590 & 58131 & 8765 \\
Age 81-90 & 2045 & 10782 & 27763 & 60123 & 9730 \\
\hline \hline
\end{tabular}

\subsection{Calibration}

I calibrate the benchmark model to the current US economy. The labor productivity parameters are determined as follows. The logarithm of the individual-specific permanent productivity shock, $\ln \epsilon$, is assumed to follow the normal distribution: $N \sim\left(0, \sigma_{\epsilon}^{2}\right)$. I discretize the distribution into five states using the method introduced in Tauchen (1986). Transforming the values back from the logarithms, I get a finite set $\left\{\epsilon_{1}, \epsilon_{2}, \epsilon_{3}, \epsilon_{4}, \epsilon_{5}\right\}$, with the corresponding probabilities. The variance of the $\log$ of the permanent productivity shock, $\sigma_{\epsilon}^{2}$, is set to 0.65 such that it is consistent with the empirical estimates of the variance of log annual earnings of men in 
Table 4: Conditional Survival Probabilities $(S)$

\begin{tabular}{lcccc}
\hline Survival Prob. (\%) & $S\left(m_{1}\right)$ & $S\left(m_{2}\right)$ & $S\left(m_{3}\right)$ & $S\left(m_{4}\right)$ \\
\hline Age 66-70 & 99.1 & 98.0 & 94.4 & 88.7 \\
Age 71-80 & 97.6 & 96.4 & 92.6 & 82.6 \\
Age 81-90 & 94.3 & 89.7 & 83.4 & 71.5 \\
\hline \hline
\end{tabular}

Heathcote, Perri and Violante (2010). The age-specific productivities, $\left\{\gamma_{j}\right\}_{j=1}^{R}$, are calculated from the earnings data in the Current Population Surveys. The calibrated results on labor productivity are reported in Tables 1 and 2 .

For simplicity, I assume that there is no mortality risk and health expenses before retirement since this paper is mainly concerned about old-age issues. That is, $S_{j}=1$ and $m_{j}=0$ for all $j \leq$ $R$. After retirement, the health expense $m$ is assumed to be governed by a 4-state Markov chain with $m=\left\{m_{1}, m_{2}, m_{3}, m_{4}\right\}$ and the transition matrix $\operatorname{Trans}(x, y)=\operatorname{Prob}\left(m_{j+1}=m_{y} \mid m_{j}=\right.$ $\left.m_{x}\right)$.

I use the MEPS dataset to calibrate the health expense shock $m$ and the corresponding survival probability $S(m) .{ }^{7}$ Specifically, I calibrate the four states for $m$ by breaking down the health expenditure distribution into four bins of sizes $(0-50 \%, 50 \%-90 \%, 90 \%-95 \%, 95 \%-$ $100 \%)$. I do so for each five- or ten-year group. Then, I calculate the transition matrices for $m$ for each age group directly from the panel data. The calibrated health expenditure levels are reported in Table 3, and the calibrated transition matrices are reported in the appendix. The corresponding survival probabilities $S_{j}\left(m_{j}\right)$ can also be calculated from the MEPS dataset, and they are reported in Table $4 .{ }^{8}$ As can be seen, the conditional survival probabilities are highly correlated with the current health expenses. For instance, the conditional survival probability to the next year for an agent within the 66-70 age group is $99.1 \%$ if her current health expense is below the 50th percentile of the distribution, but her survival probability would decrease to $88.7 \%$ if her current health expense is above the 95th percentile of the distribution. Similar results can also be found for other age groups. Note that the main purpose of this paper is to show that this correlation between survival probability and health expenses is important for understanding the agent's behaviors, i.e., the demand for health insurance and annuities, and precautionary saving.

On the government side, I set the Social Security tax rate $\tau_{s}$ to $12.4 \%$ according to the

\footnotetext{
${ }^{7}$ Specifically, I use all the waves of the panel data after 2000, i.e., 2001-2002, 2002-2003, 2003-2004, 2004-2005, 2005-2006, 2006-2007, 2007-2008, 2008-2009, 2009-2010.

${ }^{8}$ The implied unconditional average survival probabilities at each age are slightly different from those in the US life table from National Vital Statistics Reports. To adjust for this difference, I scale all survival probabilities at each age proportionally.
} 
SSA data. The benefit formulae $S S\left(\epsilon_{i}\right)$ are assumed to have the same structure as in Fuster, Imrohoroglu, and Imrohoroglu (2007) so that the program captures the progressivity of the US Social Security program. I rescale every beneficiary's benefits so that the Social Security program is self-financing. According to the CMS data, approximately $50 \%$ of the elderly's health expenditures are paid by Medicare, thus I set the Medicare coinsurance rate $\kappa_{m}$ to $0.5 .^{9}$ The Medicare payroll tax rate $\tau_{m}$ is endogenously determined by Medicare's self-financing budget constraint. I set the value of the consumption floor $\underline{c}$ to $\$ 2663$ based on the estimation in De Nardi, French, and Jones (2010), and then endogenously determine the value of $\tau_{w}$.

As for the prices, the interest rate is set to $4 \%$, and the wage rate $w$ is chosen so that the output per capita in the model is consistent with the US GDP per capita. The value of the discount factor $\beta$ is chosen to match the capital-output ratio in the US, i.e., 3.0. The rest of the parameter values are directly determined based on the estimates in the standard dynamic macroeconomics literature. That is, the elasticity parameter in the CRRA utility function, $\sigma$, is set to 2 . Table 5 summarizes the calibrated parameter values.

Since the model is complicated and cannot be solved analytically, I solve it using numerical techniques. Specifically, I solve the decision rules for agents backward from the last period. Some key statistics of the calibrated economy are reported in Table 6. As can be seen, the calibrated model is consistent with the data along most dimensions. For instance, both the output per capita and the capital-output ratio closely match the data. Health expenses per elderly person and the Medicare tax rate are on the slightly higher side, which is partly due to that the population structure at steady state does not exactly match the current U.S. population distribution. ${ }^{10}$ One exception is the fraction of elderly people on welfare, which is somehow significantly lower than in the data. This is probably due to the simplifying assumptions made in the analysis such as no idiosyncratic earnings shock and exogenous labor supply, which understate the risk facing agents in the model. The life cycle profiles of saving and consumption for an average agent in the model are plotted in Figure 1.

\section{$5 \quad$ Main Quantitative Results}

\section{$5.1 \quad$ Health Insurance}

To understand the impact of the correlation between health expenses and survival probabilities on the demand for health insurance, I now introduce a health insurance market into the benchmark economy. I assume that the health insurance market offers a menu of actuarially-fair

\footnotetext{
${ }^{9}$ See Attanasio, Kitao, and Violante (2008) for a detailed description of Medicare.

${ }^{10}$ Note that another reason why the Medicare tax rate in the model is higher is because I do not model the Medicare premiums and therefore a slightly higher tax rate is needed for the Medicare program to be self-financing.
} 
Table 5: Benchmark Calibration

\begin{tabular}{llll}
\hline Parameter & Description & Value & Target/Source \\
\hline$\sigma$ & CRRA utility parameter & 2 & Macro literature \\
$r$ & interest rate & $4 \%$ & Macro literature \\
$\beta$ & subjective discount factor & 0.96 & Capital-output ratio: 3.0 \\
$w$ & wage & $\$ 25,000$ & GDP per capita in 2006: $\$ 46444$ \\
$\tau_{s}$ & Social Security tax & $12.4 \%$ & SSA data \\
$\kappa_{m}$ & Medicare Coin. rate & $50 \%$ & CMS data \\
$\underline{c}$ & consumption floor & $\$ 2663$ & De Nardi, French and Jones $(2010)$ \\
\hline
\end{tabular}

Table 6: Some Key Statistics of the Calibrated Model

\begin{tabular}{lll}
\hline Statistic & Value & Data \\
\hline Output per capita & $\$ 46790$ & $\$ 46444$ \\
Capital-output ratio & 3.0 & 3.0 \\
Health Expenses per elderly person & $\$ 9245$ & $\$ 8657$ \\
Medicare tax $\tau_{m}$ & $4.3 \%$ & $2.9 \%$ \\
Fraction of the elderly on welfare & $1.3 \%$ & $10.1 \%$ \\
Welfare tax $\tau_{w}$ & $0.1 \%$ &.. \\
\hline
\end{tabular}

policies with a coinsurance rate ranging from $0 \%$ to $100 \%$. The policy with a coinsurance rate $I$ will cover $I$ fraction of the health expenses uncovered by Medicare in each period over the remainder of the holder's life, and meanwhile the holders of the policy are required to pay a premium in each period. For simplicity, I assume that agents have access to the health insurance market only once in their lives, that is, at age $j=R$ (right before retirement). In addition, I assume that agents can only insure uncertain health expenses with those in their own age cohort. ${ }^{11}$ As a result, the premium at each age can be simply expressed as $q_{I}^{j}=I\left(1-\kappa_{m}\right) E\left(m_{j}\right)$ for all $j>40$. That is, the premium at each age is the $I$ fraction of the expected average health expense uncovered by Medicare at that age.

In the model with health insurance, agents at age $j<40$ face the same problem as in the benchmark model. At age $j=40$, the utility-maximization problem facing agents is as follows.

$$
V\left(j, a_{j}, m_{j}, \epsilon_{i}\right)=\max _{c_{j}, a_{j+1}, I} \frac{c_{j}^{1-\sigma}}{1-\sigma}+\beta E\left[S_{j}\left(m_{j}\right) V\left(j+1, a_{j+1}, m_{j+1}, \epsilon_{i}, I\right)\right]
$$

subject to

$$
a_{j+1}+c_{j}+m_{j}=w \gamma_{j} \epsilon_{i}\left(1-\tau_{s}-\tau_{m}-\tau_{w}\right)+a_{j}(1+r)+b+t r
$$

\footnotetext{
${ }^{11}$ Note that all agents at age $j=40$ have zero health expense (no pre-existing condition), thus there is no adverse selection in the health insurance market.
} 


$$
a \geq 0 \text { and } c \geq 0
$$

Note that here agents after retirement would have one more state variable, $I$, which indicates the type of health insurance policy purchased at age $j=R$. After retirement $(j>40)$, the agent's problem is,

$$
V\left(j, a_{j}, m_{j}, \epsilon_{i}, I\right)=\max _{c_{j}, a_{j+1}} \frac{c_{j}^{1-\sigma}}{1-\sigma}+\beta E\left[S_{j}\left(m_{j}\right) V\left(j+1, a_{j+1}, m_{j+1}, \epsilon_{i}, I\right)\right]
$$

subject to

$$
\begin{gathered}
a_{j+1}+c_{j}+(1-I)\left(1-\kappa_{m}\right) m_{j}+q_{I}^{j}=S S\left(\epsilon_{i}\right)+a_{j}(1+r)+t r \\
a \geq 0 \text { and } c \geq 0
\end{gathered}
$$

I compute the agent's problem backward from the last period. The health insurance decisions are reported in Table 7. As can be seen, agents do not choose to buy a health insurance policy with a $100 \%$ coinsurance rate, though the health insurance market is frictionless. On average, agents choose to insure $66.3 \%$ of their uncertain health expenses. To quantify the impact of the correlation between health expense and survival probabilities on the demand for health insurance, I run a counterfactual computational experiment in which I assume away the correlation between survival probability and health expense. That is, I reset the survival probability for every agent at each age to be the same as the average survival probability at that age, and then I recompute the agents' health insurance decisions. As also shown in Table 7, now agents on average choose to insure $91.1 \%$ of their uncertain health expenses. The comparison between the counterfactual results and the benchmark results suggests that the correlation between health expenses and survival probabilities has a large negative effect on the demand for health insurance. This also suggests that the correlation between health expenses and survival probabilities may be important for understanding the optimal insurance arrangements for health expense shocks.

As argued before, the correlation between health expenses and survival probabilities should have a larger impact on richer agents. Since richer agents tend to consume more per period, for the same reduction in longevity, the resources freed up for them should also be higher, and therefore are more likely to be enough to compensate for the simultaneous increase in health expenses. Table 7 also demonstrates the health insurance decisions by income. As can be seen, the relationship between the coinsurance rate and income in the model is nonmonotone. The agents at the two ends of the distribution purchase less health insurance than those in the middle. Why doesn't the coinsurance rate decrease monotonically with income? To understand this non-monotone relationship, it is important to note that there is another reason why agents do not fully insure against uncertain health expenses in the model, that is, 
the welfare program. The welfare program provides partial insurance against uncertain health expenses by guaranteeing a minimum consumption floor, thus it also reduces the demand for private health insurance. Since poorer agents are more likely to fall on the consumption floor, the welfare program reduces their demand for health insurance proportionally more. To verify this point, I consider a counterfactual model in which the welfare program is removed. ${ }^{12}$ The results in this counterfactual model are also reported in Table 7. As can be seen, the coinsurance rate decreases monotonically as the income rises now. While the agents with the lowest productivity choose to insure $94.9 \%$ of their health expenses, the agents with the highest productivity choose to only insure $30.8 \%$ of their uncertain health expenses. When the correlation between health expenses and survival probabilities is also assumed away, everyone chooses to fully insure their uncertain health expenses.

Figure 1 plots the life cycles of consumption and saving for an average agent in the models with and without health insurance. As can be seen, the life cycle profiles look similar in both models. Agents in the model with health insurance accumulate slightly less savings during the working period and dissave faster after retirement because uncertain health expenses are partially covered by health insurance in this model. For the same reason, the consumption near the end of life is lower in this model because agents keep less precautionary savings untill the maximum possible age.

Table 7: Health Coinsurance Rates: I

\begin{tabular}{lcccccc}
\hline & $\epsilon_{1}$ & $\epsilon_{2}$ & $\epsilon_{3}$ & $\epsilon_{4}$ & $\epsilon_{5}$ & Average \\
\hline Benchmark & $0 \%$ & $87.2 \%$ & $79.5 \%$ & $61.5 \%$ & $30.8 \%$ & $66.3 \%$ \\
No correlation & $0 \%$ & $100 \%$ & $100 \%$ & $100 \%$ & $100 \%$ & $91.1 \%$ \\
\hline & & & & & & \\
\hline Benchmark with no welfare program & $94.9 \%$ & $87.2 \%$ & $79.5 \%$ & $61.5 \%$ & $30.8 \%$ & $74.8 \%$ \\
No correlation & $100 \%$ & $100 \%$ & $100 \%$ & $100 \%$ & $100 \%$ & $100 \%$ \\
\hline
\end{tabular}

\subsection{Annuities}

In this section, I introduce an annuity market into the benchmark model, and use the extended model to study the impact of the correlation between health expenses and survival probabilities on the demand for annuities. ${ }^{13}$ The structure of the annuity market is designed as follows. The

\footnotetext{
${ }^{12}$ Note that a complete removal of the welfare program would make the model not well-defined. That is, there exists a tiny fraction of the population which is extremely unlucky (hit by a bad productivity shock and a series of bad health expense shocks) and does not have enough resources to cover its health expenses. As a result, I set the minimum consumption floor in the counterfactual model to $\$ 100$. As a robustness check, I also explore other values (i.e., $\$ 50, \$ 10$ ) and find that the main results do not significantly change.

${ }^{13}$ The health insurance market is closed in this section so that I can focus on the demand for annnuities.
} 
annuities are actuarially-fair and they are accessible to any agent after retirement. In addition, I assume that agents can both buy and sell their annuities in the market. Note that with this assumption, uncertain health expenses would not affect the demand for annuities due to the liquidity constraint, therefore I can identify the impact of the correlation between health expenses and longevity on the demand for annuities. ${ }^{14}$ Since the market is frictionless, the price of an annuity policy should be conditioned on both age $j$ and current health expense $m_{j}$. That is, the price of a policy paying one dollar annuity in each period over the rest of the life is described as,

$$
q_{A}\left(j, m_{j}\right)=\sum_{L=j+1}^{T} \frac{E_{j}\left[\prod_{i=j}^{L-1} S_{i}\left(m_{i}\right) \mid m_{j}\right]}{(1+r)^{L-j}}
$$

In this version of the model, agents face the same problem as in the benchmark model without annuities before retirement $(j \leq R)$. After retirement, the utility-maximization problem facing agents can be described as follows.

$$
V\left(j, a_{j}, m_{j}, \epsilon_{i}, A_{j}\right)=\max _{c_{j}, a_{j+1}, A_{j+1}} \frac{c_{j}^{1-\sigma}}{1-\sigma}+\beta E\left[S_{j}\left(m_{j}\right) V\left(j+1, a_{j+1}, m_{j+1}, \epsilon_{i}, A_{j+1}\right)\right]
$$

subject to

$$
\begin{gathered}
a_{j+1}+c_{j}+\left(1-\kappa_{m}\right) m_{j}+q_{A}\left(j, m_{j}\right) A_{j+1}=S S\left(\epsilon_{i}\right)+q_{A}\left(j, m_{j}\right) A_{j}+a_{j}(1+r)+A_{j} \\
a \geq 0 \text { and } c \geq 0
\end{gathered}
$$

Note that there is one more state variable, $A$, for the agent's holding of annuities after retirement. In addition, at age $j=41$, the value of $A$ is zero for everyone as the annuity market is not accessible to agents at age $j \leq 40$.

Again, I compute the agent's problem backward from the last period. The results on annuitization are reported in Table 8. Here the measure for annuitization I use is the annuitized wealth as a share of total wealth, that is, $\frac{q_{A}\left(j, m_{j}\right) A_{j+1}}{a_{j+1}+q_{A}\left(j, m_{j}\right) A_{j+1}}$. As can be seen, agents do not fully annuitize their wealth, though the annuity policies are actuarially-fair. On average, agents choose to annuitize $91.5 \%$ of their retirement wealth (wealth at age $j=41$ ). However, when the correlation between health expenses and survival probabilities is assumed away, everyone chooses full annuitization. The intuition behind this result is similar to that for health insurance decisions. That is, since the survival probability is negatively correlated with the health expense, the agent hit by a lower health expense shock also experiences an increase in her ex-

\footnotetext{
${ }^{14}$ In reality, annuities may be not as liquid as in the model and individuals cannot freely sell back their annuities in the market. Thus, the model here may have overstated the optimal demand for annuities. If agents are not allowed to sell back annuities in the market, their demand for annuitization would be even lower than what has been found in the model.
} 
pected longevity. Thus, she can simply use the reduced amount of health expense to cover the consumption in the increased period of life.

The results on annuitization can also be explained by using the pricing function for annuities, $q_{A}\left(j, m_{j}\right)$. As shown at the beginning of Section $5.2, q_{A}\left(j, m_{j}\right)$ is decreasing in $m_{j}$. That is, the market value of annuity asset would decrease if its holder gets hit by a bad health shock (i.e., a high value of $\left.m_{j}\right) .{ }^{15}$ This implies that holding annuities would amplify the health expense risks facing agents. In other words, annnuities are implicitly negative health insurance. Therefore, agents may not want to fully annuitize their wealth when they face significant health expense risks. Their optimal demand for annuities depends on the tradeoff between the longevity insurance benefit provided by annuities and the loss they generate by amplifying the health expense risks. Note that health expense risks are usually less important for richer agents as they have more savings. Thus, the mechanism emphasized here should have a smaller impact on richer agents. This implication is confirmed by the quantitative results presented in Table 8. As can be seen, the least productive agents annuitize only $64.0 \%$ of their retirement wealth, while the most productive agents choose full annuitization.

It is also worth noting that the impact on the demand for annuities is quantitatively small. In the model, most agents still choose to annuitize a major portion of their wealth, which is not the case in the data. For instance, Lockwood (2013) finds that the average annuity ownership rate is only $6 \%$ in the Health and Retirement Study(HRS) dataset. This suggests that the correlation between health expenses and survival probabilities may not be an important reason why so many Americans do not buy annuities, and there must exist other explanations that are more important for accounting for the non-annuitization in the data. ${ }^{16}$

Figure 2 plots the life cycles of consumption and savings for an average agent in the models with and without annuities (note that here the savings include both assets). As can be seen, agents in the model with annuities save slightly less than those in the model without annuities before retirement, but after retirement they dissave more slowly and thus after age 75 they hold more savings than in the model without annuities. The intuition behind this is simple. In the model with annuities, as the decreasing survival probability after retirement is offset by the increasing return on annuities, agents tend to dissave more slowly after retirement. However, annuitization also reduces accidental bequests, therefore they receive less bequest transfer during the working age. As a result, agents in the model with annuities save slightly less before retirement. The consumption profiles are also different in the two models. In the model with annuities, the consumption profile does not significantly decreases after retirement,

\footnotetext{
${ }^{15}$ For instance, in the calibrated model, the price of $\$ 1$ annuity at age $j=41$ is $\$ 11.4$ for individuals with the lowest health expense, while the price is $17 \%$ lower (i.e., $\$ 9.5$ ) for agents with the highest health expense.

${ }^{16}$ See Pashchenko (2013) for a comprehensive review of the literature on the annuity puzzle.
} 
while it declines quickly after retirement in the model without annuities. The intuition for this result is similar to that for the savings profiles. The return on annuities increases as age increases and the survival probability declines. Therefore, simply according to the Euler equation, the consumption path in the model with annuities should not decline as much as in the model without annuities (see Davies, 1981).

Table 8: Annuitized Wealth As A Share of Total Wealth at Retirement

\begin{tabular}{lcccccc}
\hline Perm. productivity & $\epsilon_{1}$ & $\epsilon_{2}$ & $\epsilon_{3}$ & $\epsilon_{4}$ & $\epsilon_{5}$ & Average \\
\hline Benchmark & $64.0 \%$ & $74.0 \%$ & $100 \%$ & $100 \%$ & $100 \%$ & $91.5 \%$ \\
No correlation & $100 \%$ & $100 \%$ & $100 \%$ & $100 \%$ & $100 \%$ & $100 \%$ \\
\hline
\end{tabular}

\subsection{Precautionary Saving}

Economists have long argued that uncertain health expenses generate precautionary saving. Recently, there has been a growing macro literature that uses quantitative dynamic models to study the impact of uncertain health expenses on precautionary saving. Most studies in this literature find that the impact of uncertain health expenses on precautionary saving is large and quantitatively important for understanding the saving and wealth data in the US. ${ }^{17}$. In this section, I ask whether the implication for precautionary saving is different when uncertain health expenses are correlated with uncertain longevity. ${ }^{18}$

It is worth mentioning that some existing studies also implicitly captured the correlation between health expenses and longevity. For instance, De Nardi, French, and Jones (2010) captured the correlation between health expenses and survival probabilities via including health status as a state variable in their model. Kopecky and Koreshkova (2009) partially captured the correlation by modelling a nursing home shock. In this paper, I assume that the survival probability is directly conditioned on current health expense, and measure the magnitude of the correlation between the health expense and survival probability from the MEPS dataset.

To quantitatively assess the implication of the correlation between health expenses and survival probabilities for precautionary saving, I conduct the following counterfactual experiment in the benchmark model: I assume away the correlation between health expenses and survival probabilities by resetting the survival probabilities for everyone at each age to be the average survival probability at that age, and then recompute the decision rules. As shown in Table 9, the

\footnotetext{
${ }^{17}$ Hubbard, Skinner, and Zeldes (1995), De Nardi, French, and Jones (2010), Kopecky and Koreshkova (2009), etc.

${ }^{18}$ Note that the findings here are also related to the papers that study the saving effects of uncertain life span, such as Davies (1981) and Leung (1994).
} 
average amount of wealth accumulated at the beginning of retirement increases by $3.5 \%$ when health expenses are assumed to be independent of survival probabilities. Across the income distribution, the retirement wealth for agents with the highest productivity only increases by $1.9 \%$, while the retirement wealth for agents with the least productivity increases by $11.5 \%$. The intuition for this result is simple: when the uncertain health expenses are correlated with the survival probabilities, the two uncertainties partially offset each other, thus generating less precautionary savings than in the model without the correlation.

Table 9: Wealth at the Beginning of Retirement (in \$1000)

\begin{tabular}{lcccccc}
\hline Perm. productivity & $\epsilon_{1}$ & $\epsilon_{2}$ & $\epsilon_{3}$ & $\epsilon_{4}$ & $\epsilon_{5}$ & Average \\
\hline Benchmark & 69 & 151 & 269 & 526 & 1137 & 365 \\
No correlation & 77 & 161 & 281 & 542 & 1158 & 378 \\
Change in $\%$ & $11.5 \%$ & $6.2 \%$ & $4.5 \%$ & $3.0 \%$ & $1.9 \%$ & $3.5 \%$ \\
\hline
\end{tabular}

\subsection{The Impact of Medicare}

It is also interesting to consider the impact of Medicare in the model. To quantitatively assess the effects of Medicare on the demand for health insurance and individual welfare, I conduct the following counterfactual experiment: I remove the Medicare program in the benchmark model with health insurance, and then recompute the individuals' decision rules and the equilibrium. As for the welfare analysis, I adopt the equivalent consumption variation (ECV) as the welfare criteria, that is, the change in consumption each period required for a new born to achieve the same expected lifetime utility. The results are reported in Table 10. As can be seen, Medicare has a significant crowding out effect on the demand for private health insurance. When the Medicare program is removed, the average private health coinsurance rate chosen increases from $66.3 \%$ to $77.0 \%$. Medicare also has a significant effect on individual welfare. In terms of the equivalent consumption variation, individual welfare increases by $5.1 \%$ when the Medicare program is removed. An important reason for this welfare result is that Medicare discourages capital accumulation and thus reduces the aggregate output as it is a pay-as-you-go program. That is, when Medicare is removed, the output per capita increases by $10.8 \%$ (i.e., from $\$ 46,743$ to $\$ 50,476)$. In addition, as can be seen, the welfare gain is relatively larger for the least productive agents. This is because the least productive agents are more likely to rely on the welfare program when hit by bad health shocks, and thus Medicare is less useful for them. Note that the welfare result obtained here should be treated with caution, because the model does not include all the relevant elements for a complete welfare analysis of Medicare and thus may not 
capture all the potential welfare effects. For instance, the model does not capture the potential frictions in the private health insurance market (such as adverse selection and administrative costs), and thus may underestimate the benefits from the insurance provided by Medicare.

Table 10: The Impact of Medicare

\begin{tabular}{lcccccc}
\hline Perm. productivity & $\epsilon_{1}$ & $\epsilon_{2}$ & $\epsilon_{3}$ & $\epsilon_{4}$ & $\epsilon_{5}$ & Average \\
\hline The demand for health insurance & & & & & & \\
\hline Benchmark & $0 \%$ & $87.2 \%$ & $79.5 \%$ & $61.5 \%$ & $30.8 \%$ & $66.3 \%$ \\
Medicare removed & $0 \%$ & $89.5 \%$ & $89.5 \%$ & $78.9 \%$ & $57.9 \%$ & $77.0 \%$ \\
\hline \hline Individual welfare (ECV) & & & & & & \\
Welfare gain (Medicare removed) & $6.7 \%$ & $4.6 \%$ & $4.6 \%$ & $4.6 \%$ & $4.6 \%$ & $5.1 \%$ \\
\hline
\end{tabular}

\subsection{Further Discussion}

The main finding of the paper is that the correlation between health expenses and survival probabilities can explain why many agents (especially the rich) do not buy more health insurance. However, it is worth mentioning that there also exist other explanations for the lack of health insurance puzzle, such as the existence of the means-tested programs and the supply-side frictions in the health insurance market. ${ }^{19}$ For instance, Brown and Finkelstein $(2007,2008)$ found that the existence of Medicaid is an important reason why individuals in the bottom half of the distribution do not buy extra health insurance, but the supply-side frictions (i.e., insurance premium markups) are quantitatively not very important.

This paper is complementary to these existing studies. As is known from the data, many rich people also do not buy extra private health insurance. As presented in Table 11, the private insurance coverage rates for individuals aged $65+$ are low among all education groups in the MEPS dataset. ${ }^{20}$ Individuals with no high school diploma are least likely to buy private health insurance, i.e., only $17.8 \%$ of them hold private health insurance. While the rest of the individuals are more likely to buy private health insurance than those without a high school diploma, the coverage rates for them are still relatively low, ranging from $32.5 \%$ to $44.7 \%$. This paper contributes to the literature providing a complementary explanation that can help explain why many rich individuals also do not want to buy additional private health insurance.

It is important to note that the model studied here also has limitations as it has left out some elements that are relevant and may be important for understanding the demand for health

\footnotetext{
${ }^{19}$ See Pauly (1990), Cutler and Gruber (1996a, 1996b), Brown and Finkelstein (2007, 2008), Lockwood (2013), etc.

${ }^{20}$ Here the private insurance coverage rate is defined as the fraction of individuals with private insurance.
} 
insurance. For instance, De Nardi, French, and Jones (2010) documented in the data that individuals with higher permanent income tend to have more health expenses and live longer. These features are not incorporated in the model, which may have led the model to miss certain dimensions of the data, i.e., the relationship between the health insurance coverage rate and the permanent income. Another limitation is that I do not model the spousal effect in this paper. If the extra private health insurance is the long term care insurance, then the informal care potentially available from family members (e.g., the spouse) could also crowd out the demand for private health insurance. ${ }^{21}$ In addition, the model does not include bequest motives. As shown in Lockwood (2013), the presence of bequest motives would decrease the demand for private insurance as bequest motives reduce the opportunity cost of precautionary saving. By leaving these channels out, the model may overestimate the demand for private health insurance. In this paper, I leave these elements out of the model because the focus of the paper is on the new mechanism, i.e., the implication of the correlation between health expenses and survival probabilities, but these channels are definitely important for a comprehensive understanding of the demand for health insurance and need more study in the future.

Table 11: Private Health Insurance Coverage Rates By Education

\begin{tabular}{l|c|c|c|c}
\hline & no high school diploma & high school graduate & some college & college graduate \\
Years of schooling & $<12$ & $12-13$ & $14-15$ & $16+$ \\
\hline Coverage rate & $17.8 \%$ & $32.5 \%$ & $39.2 \%$ & $44.7 \%$ \\
\hline
\end{tabular}

(Data source: MEPS)

\section{Conclusion}

This paper studies a dynamic life cycle model with health shocks that can simultaneously increase health expenses and reduce longevity. I show that rational agents would neither fully insure their uncertain health expenses nor fully annuitize their wealth because the correlation between health expenses and longevity provides a self insurance channel for both uncertainties. That is, when the agent is hit by a health shock (which simultaneously increases health expenses and reduces longevity), she can use the resources originally saved for consumption in the reduced period of life to pay for the increased health expenses. Since the two uncertainties partially offset each other, the precautionary saving generated in the model should be smaller than in a standard

\footnotetext{
${ }^{21}$ As shown in Kopecky and Koreshkova (2009) among others, an important type of health expenses facing the elderly but not covered by Medicare is long term care expenses. Thus, long term care insurance is one of the most important additional private health insurance types available to the elderly.
} 
model without the correlation between health expenses and longevity. I calibrate the model using the MEPS dataset, and find that the health expenses are highly correlated with the survival probabilities. The quantitative exercises suggest that the correlation between health expenses and survival probabilities significantly reduces the demand for actuarially-fair health insurance, while its impact on the demand for annuities and precautionary saving is relatively small.

\section{References}

Attanasio, O., S. Kitao, and G. L. Violante (2008): "Financing Medicare: A General Equilibrium Analysis," in Demography and Economics, edited by J. Shoven, NBER.

Brown, J., And A. Finkelstein (2007): "Why Is the Market for Long Term Care Insurance so Small," Journal of Public Economics, 91(10), 1967-1991.

(2008): "The Interaction of Public and Private Insurance: Medicaid and the Long-Term Insurance Market," American Economic Review, 98(3), 1083-1102.

Cutler, D. M., And J. Gruber (1996a): "Does Public Insurance Crowd Out Private Insurance?," Quarterly Journal of Economics, 111(2), 391-430.

(1996b): "The Effect of Expanding the Medicaid Program on Public Insurance, Private Insurance, and Redistribution," American Economic Review, 86(2), 368-373.

DAvies, J. B. (1981): "Uncertain Lifetime, Consumption, and Dissaving in Retirement," Journal of Political Economy, 89, 561-577.

DeNardi, M., E. French, and J. Jones (2010): "Why Do the Elderly Save? The Role of Medical Expenses," Journal of Political Economy, 118(1), 39-75.

Fuster, L., A. Imrohoroglu, and S. Imrohoroglu (2007): "Elimination of Social Security in a Dynastic Framework," Review of Economic Studies, 74(1).

Gruber, J. (2008): "Covering the Uninsured in the United States," Journal of Economic Literature, 46(3), 571-606.

Heathcote, J., F. Perri, and G. L. Violante (2010): "Unequal we stand: An empirical analysis of economic inequality in the United States, 1967-2006," Review of Economic Dynamics, 13(1), 15-51.

Hubbard, R. G., J. Skinner, And S. P. Zeldes (1995): "Precautionary Saving and Social Insurance," Journal of Political Economy, 103(2). 
Hurd, M., D. McFadden, And A. Merrill (2001): "Predictors of Mortality among the Elderly," NBER Chapters, in: Themes in the Economics of Aging, 171-198.

Kimball, M. (1990): "Precautionary Saving in the Small and in the Large," Econometrica, pp. $53-73$.

Kopecky, K. A., and T. Koreshkova (2009): "The Impact of Medical and Nursing Home Expenses and Social Insurance Policies on Savings and Inequality," unpublished manucript, University of Western Ontario.

Kotlikoff, L. J., And A. Spivak (1981): "The Family as an Incomplete Annuities Market," Journal of Political Economy, 89(2).

Leland, H. E. (1968): "Saving and Uncertainty: The Precautionary Demand for Saving," Quarterly Journal of Economics, 82, 465-473.

Leung, S. F. (1994): "Uncertain Lifetime, the Theory of the Consumer, and the Life Cycle Hypothesis," Econometrica, 62(5).

Lockwood, L. M. (2011): "Bequest Motives and the Annuity Puzzle," Review of Economic Dynamics, forthcoming.

(2013): "Incidental Bequests: Bequest Motives and the Choice to Self-Insure Late-Life Risks," unpublished manuscript, Northwestern University.

Pashchenko, S. (2013): "Accounting for Non-annuitization," Journal of Public Economics, $98,53-67$.

Pauly, M. V. (1990): "The Rational Nonpurchase of Long-Term-Care Insurance," Journal of Political Economy, 98(1).

Sinclair, S. H., And K. A. Smetters (2004): "Health Shocks and the Demand for Annuities," 2004-9, Congressional Budget Office.

Tauchen, G. (1986): "Finite State Markov Chain Approximations to Univariate and Vector Autoregressions," Economics Letters, 20, 177-181.

YAARI, M. E. (1965): "Uncertain Lifetime, Life Insurance, and the Theory of the Consumer," Review of Economic Studies, 32(2), 137-150.

Yogo, M. (2009): "Portfolio Choice in Retirement: Health Risk and the Demand for Annuities, Housing, and Risky Assets," NBER working paper 15307. 
Zнао, K. (2014): "Social Insurance, Private Health Insurance and Individual Welfare," working paper, University of Connecticut. 
Figure 1: Life Cycle Profiles in the Models with and without Health Insurance

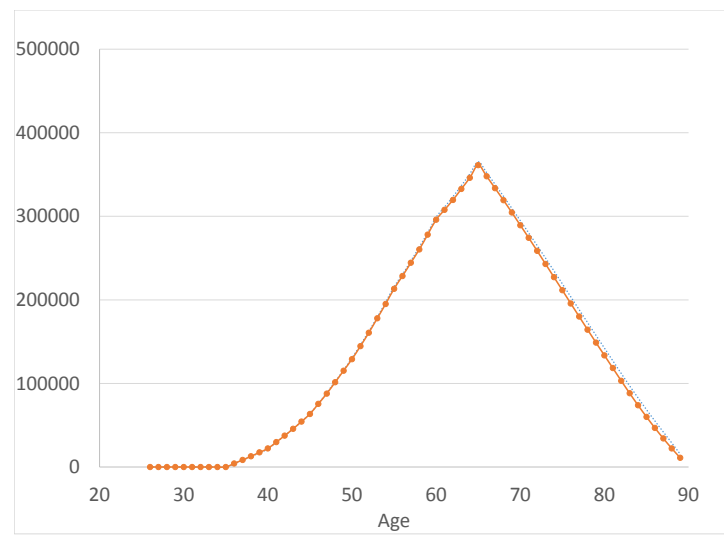

(a) Savings Profile

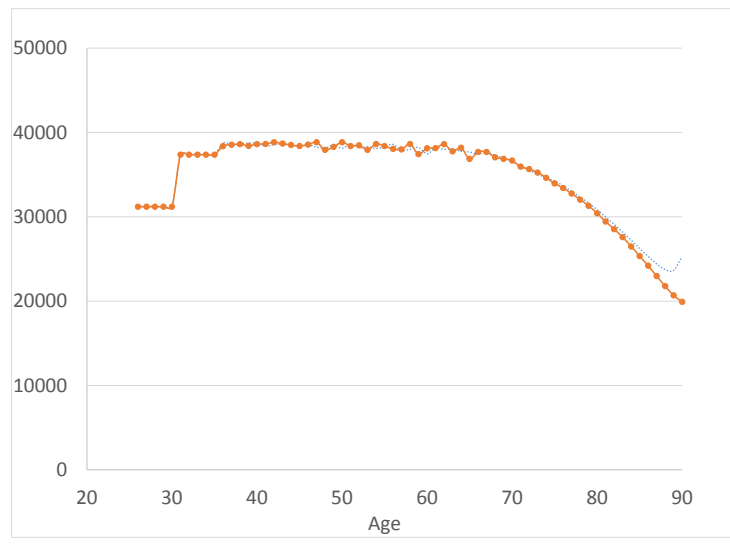

(b) Consumption Profile

(Note: the solid lines represent the profiles in the model with health insurance, while the dash lines are for the model without health insurance.)

Figure 2: Life Cycle Profiles in the Models with and without Annuities

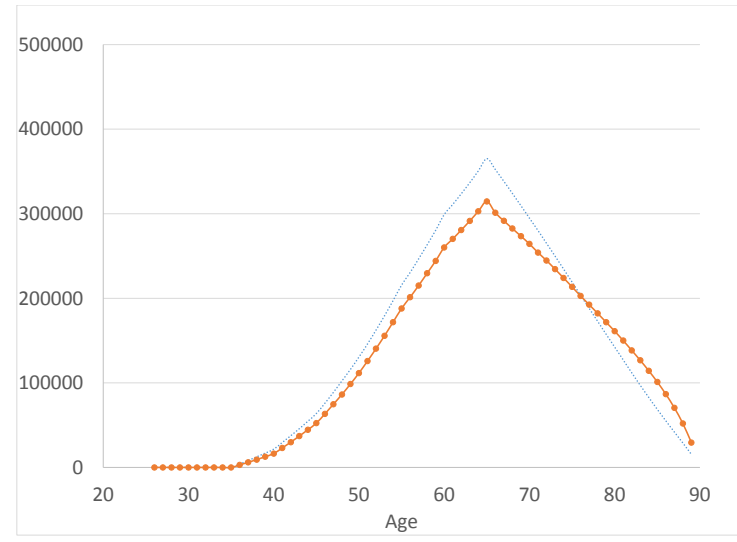

(a) Savings Profile

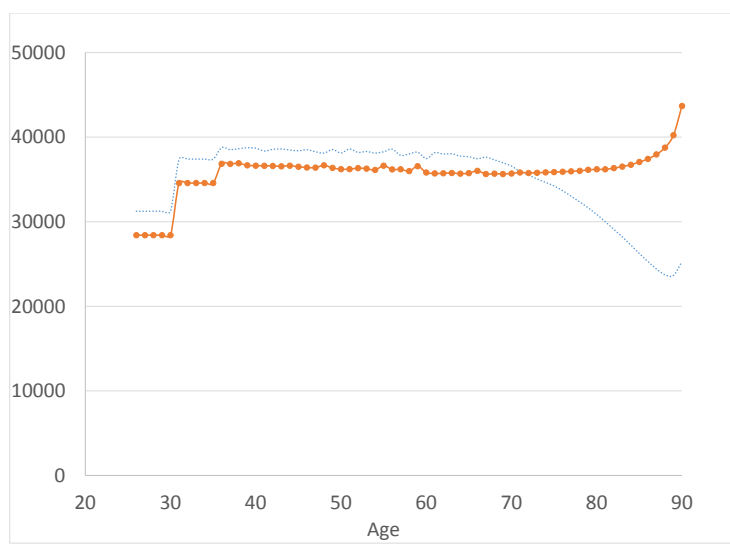

(b) Consumption Profile

(Note: the solid lines represent the profiles in the model with annuities, while the dash lines are for the model without annuities.)

\section{Appendix I: The Analytical Model with Precautionary Saving}

In this appendix, I extend the analytical model in section 3 by introducing a working period before retirement, and use it to derive some theoretical results for saving. The length of the working period is normalized to one, so the length of retirement, $T(h)$, measures the relative length of retirement compared to work. In the working period, each agent receives income $\mathrm{Y}$, and after that she chooses consumption for that period, $C_{1}$, and savings for retirement, 
$W=Y-C_{1}$. In the retirement period, agents face the same problem as in the benchmark model. It is assumed that private markets for annuities and health insurance are closed. Agents face the following expected utility maximizing problem,

$$
\max _{W, C_{1}, C_{2}(h)} U\left(C_{1}\right)+E\left[T(h) U\left(C_{2}(h)\right)\right]
$$

subject to

$$
\begin{gathered}
Y-W=C_{1} \\
W=M(h)+T(h) C_{2}(h), \forall h
\end{gathered}
$$

Substituting the budget constraints into the objective function, the first order condition w.r.t. $W$ can be derived,

$$
U^{\prime}\left(Y-W^{*}\right)=E U^{\prime}\left(\frac{W^{*}-M(h)}{T(h)}\right)
$$

The above equation describes the optimal saving decision, $W^{*}$.

For the convenience of the analysis, I assume that health expenses and longevity have the following properties: $M\left(h_{g}\right)=M-\frac{P}{1-P} \Delta_{M}, M\left(h_{b}\right)=M+\Delta_{M}$, and $T\left(h_{g}\right)=T+\Delta_{T}$, $T\left(h_{b}\right)=T-\frac{1-P}{P} \Delta_{T}$. This assumption implies that the expected health expense (equal to $\mathrm{M}$ ) is independent of $\Delta_{M}$ and the expected longevity (equal to T) is independent of $\Delta_{T}$. As a result, the equation determining the optimal saving decision (equation (26)) becomes,

$$
U^{\prime}\left(Y-W^{*}\right)=(1-P) U^{\prime}\left(C_{2}^{*}\left(h_{g}\right)\right)+P U^{\prime}\left(C_{2}^{*}\left(h_{b}\right)\right),
$$

where $C_{2}^{*}\left(h_{g}\right)=\frac{W^{*}-M+\frac{P}{1-P} \Delta_{M}}{T+\Delta_{T}}$, and $C_{2}^{*}\left(h_{b}\right)=\frac{W^{*}-M-\Delta_{M}}{T-\frac{1-P}{P} \Delta_{T}}$.

To understand how uncertain health expenses affect saving in the model, I simply look at the effect of a marginal increase in $\Delta_{M}$ on $W^{*}$, i.e., $\frac{\partial W^{*}}{\partial \Delta_{M}}$. To derive $\frac{\partial W^{*}}{\partial \Delta_{M}}$, I use the implicit function theorem. Setting $F=-U^{\prime}\left(Y-W^{*}\right)+(1-P) U^{\prime}\left(C_{2}^{*}\left(h_{g}\right)\right)+P U^{\prime}\left(C_{2}^{*}\left(h_{b}\right)\right)$,

$$
\frac{\partial W^{*}}{\partial \Delta_{M}}=-\frac{\partial F / \partial \Delta_{M}}{\partial F / \partial W}=-\frac{(1-P) U^{\prime \prime}\left(C_{2}^{*}\left(h_{g}\right)\right) \frac{P}{\left(T+\Delta_{T}\right)(1-P)}-P U^{\prime \prime}\left(C_{2}^{*}\left(h_{b}\right)\right) \frac{1}{T-\frac{1-P}{P} \Delta_{T}}}{U^{\prime \prime}\left(Y-W^{*}\right)+\frac{(1-P) U^{\prime \prime}\left(C_{2}^{*}\left(h_{g}\right)\right)}{T+\Delta_{T}}+\frac{P U^{\prime \prime}\left(C_{2}^{*}\left(h_{b}\right)\right)}{T-\frac{1-P}{P} \Delta_{T}}}
$$

Since $U^{\prime \prime}<0$, the denominator in the above equation is negative. Hence, the sign of $\frac{\partial W^{*}}{\partial \Delta_{M}}$ is equivalent to the sign of the numerator,

$$
(1-P) U^{\prime \prime}\left(C_{2}^{*}\left(h_{g}\right)\right) \frac{P}{\left(T+\Delta_{T}\right)(1-P)}-P U^{\prime \prime}\left(C_{2}^{*}\left(h_{b}\right)\right) \frac{1}{T-\frac{1-P}{P} \Delta_{T}} .
$$

After some simple algebraic manipulation, the following proposition can be obtained. 
Proposition 3: (1) Uncertain health expenses reduce precautionary saving, i.e., $\frac{\partial W^{*}}{\partial \Delta_{M}}<0$, if the following condition holds,

$$
U^{\prime \prime}\left(C_{2}^{*}\left(h_{g}\right)\right)\left[\frac{T-\frac{1-P}{P} \Delta_{T}}{\left(T+\Delta_{T}\right)}\right]-U^{\prime \prime}\left(C_{2}^{*}\left(h_{b}\right)\right)<0 .
$$

Note that when the condition (30) does not hold, the effect of uncertain health expenses on precautionary saving would be either positive or nil, which is the standard answer in the literature.

To better understand the intuition behind the negative effect of uncertain health expenses on precautionary saving (described in proposition 3), I consider the following two scenarios in which condition (30) holds:

(1) $U^{\prime \prime}\left(C_{2}^{*}\left(h_{g}\right)\right)<U^{\prime \prime}\left(C_{2}^{*}\left(h_{b}\right)\right)$. In this case, $C_{2}^{*}\left(h_{g}\right)<C_{2}^{*}\left(h_{b}\right)$ as $U^{\prime \prime \prime}()>0$. That is, the second-period consumption after a bad health shock is even higher than that after a good health shock. The reason for that is the resources originally saved for the long life are more than enough to cover the extra health expenses after a bad health shock. As a result, an increase in the uncertainty of health expenses even improves consumption smoothing across states, thus reducing precautionary saving.

(2) $U^{\prime \prime}\left(C_{2}^{*}\left(h_{g}\right)\right) \geq U^{\prime \prime}\left(C_{2}^{*}\left(h_{b}\right)\right)$ but $\left[\frac{T-\frac{1-P}{P} \Delta_{T}}{\left(T+\Delta_{T}\right)}\right]<\frac{U^{\prime \prime}\left(C_{2}^{*}\left(h_{b}\right)\right)}{U^{\prime \prime}\left(C_{2}^{*}\left(h_{g}\right)\right)}$. In this case, the intuition behind the negative effect of uncertain health expenses on precautionary saving is less obvious. As can be seen, $C_{2}^{*}\left(h_{g}\right)>C_{2}^{*}\left(h_{b}\right)$ in this case as $U^{\prime \prime \prime}()>0$. That is, the second-period consumption after a bad health shock is lower than that after a good health shock, and thus an increase in the uncertainty of health expenses should reduce consumption smoothing across states. However, why does it not increase precautionary saving? The intuition for that is as follows. According to the existing literature on precautionary saving (e.g., Leland (1968), Kimball (1990)), precautionary saving increases (decreases) when the shock increases (decreases) the expected marginal utility function in the second period $\left(E U^{\prime}\right)$. In a standard framework (in which the health shock does not also affect longevity), the first order derivative of the expected marginal utility function with respect to the uncertainty of health expenses (measured by $\left.\Delta_{M}\right)$ is $P\left[U^{\prime \prime}\left(C_{2}^{*}\left(h_{g}\right)\right)-U^{\prime \prime}\left(C_{2}^{*}\left(h_{b}\right)\right)\right]$. Thus, as long as $C_{2}^{*}\left(h_{g}\right)>C_{2}^{*}\left(h_{b}\right)$, an increase in the uncertainty of health expenses increases precautionary saving. However, in this model, the first order derivative of the expected marginal utility function with respect to $\Delta_{M}$ is $P\left[U^{\prime \prime}\left(C_{2}^{*}\left(h_{g}\right)\right) \frac{1}{T+\Delta_{T}}-U^{\prime \prime}\left(C_{2}^{*}\left(h_{b}\right)\right) \frac{1}{T-\frac{1-P}{P} \Delta_{T}}\right]$. As $\frac{1}{T+\Delta_{T}}<\frac{1}{T-\frac{1-P}{P} \Delta_{T}}$, even when $C_{2}^{*}\left(h_{g}\right)>C_{2}^{*}\left(h_{b}\right)$, the first order derivative of the expected marginal utility function may be negative. Specifically, when $\left[\frac{T-\frac{1-P}{P} \Delta_{T}}{\left(T+\Delta_{T}\right)}\right]<\frac{U^{\prime \prime}\left(C_{2}^{*}\left(h_{b}\right)\right)}{U^{\prime \prime}\left(C_{2}^{*}\left(h_{g}\right)\right)}$, the health shock decreases the expected marginal utility in the second period, although it improves consumption smoothing across states. As a result, uncertain health expenses reduce precautionary 
saving.

It is worth noting that everything else being equal, condition (30) is more likely to hold for richer households. In other words, the effect of uncertain health expenses on precautionary saving is more likely to be negative for them. This result can be easily obtained by looking at the marginal effect of $W$ on the left-hand side of condition (30). Substituting $C_{2}^{*}\left(h_{g}\right)=$ $\frac{W^{*}-M+\frac{P}{1-P} \Delta_{M}}{T+\Delta_{T}}$ and $C_{2}^{*}\left(h_{b}\right)=\frac{W^{*}-M-\Delta_{M}}{T-\frac{1-P}{P} \Delta_{T}}$ into the left-hand side of condition (30) and taking its first order derivative w.r.t. $W$, I find that the left-hand side of condition (30) decreases in $W$. This implies that condition (30) is more likely to hold for agents with a higher value of $W$. This implication is of particular interest because a major portion of aggregate saving is from the rich. As a result, the negative savings effect of uncertain health expenses may be not only a qualitative result, but also quantitatively relevant for understanding the effect of health expenses on aggregate capital accumulation.

\section{Appendix II}

\subsection{Data and Calibration Details}

Here I provide additional information regarding the MEPS panel dataset used in the calibration. I make use of nine waves of the panel data since 2000, that is, 2001-2002, 2002-2003, 2003-2004, 2004-2005, 2005-2006, 2006-2007, 2007-2008, 2008-2009, and 2009-2010. I stack observations in all these waves of the data into a large dataset and convert all nominal values into 2006 dollars. The MEPS dataset provides a good measure of the total health expenditure, i.e., "totexpy1" and "totexpy2". I calibrate the four states for $m$ by breaking down the total health expenditure distribution into four bins of sizes (0-50\%; 50\%-90\%; 90\%-95\%; 95\%-100\%). I do so for each of the following age groups, 66-70, 71-80, and 81-90. Then, I compute the corresponding transition matrix for the health expense shock directly from the panel data. Table 12 presents the number of observations in the dataset.

Table 12: MEPS Data Sample Size

\begin{tabular}{c|c|c|c|c|c}
\hline $\begin{array}{c}\text { No. of observations } \\
\text { by health shock }\end{array}$ & $\begin{array}{c}m_{1} \\
(0-50 \%)\end{array}$ & $\begin{array}{c}m_{2} \\
(50 \%-90 \%)\end{array}$ & $\begin{array}{c}m_{3} \\
(90 \%-95 \%)\end{array}$ & $\begin{array}{c}m_{4} \\
(95 \%-100 \%)\end{array}$ & total \\
\hline Age 66-70 & 2171 & 1738 & 217 & 217 & 4243 \\
Age 71-80 & 3397 & 2718 & 340 & 340 & 6795 \\
Age 81-90 & 1571 & 1256 & 156 & 158 & 3141 \\
\hline
\end{tabular}

The calibrated results for the health expense grids are reported in Table 3 and the corresponding transition matrices are reported in the following tables. 
Table 13: The Transition Matrix for $m$ : Age 66-70

\begin{tabular}{c|c|c|c|c}
\hline$m^{\prime}=$ & $m_{1}$ & $m_{2}$ & $m_{3}$ & $m_{4}$ \\
\hline \hline$m_{1}$ & 0.703 & 0.251 & 0.025 & 0.022 \\
$m_{2}$ & 0.294 & 0.567 & 0.063 & 0.076 \\
$m_{3}$ & 0.129 & 0.512 & 0.115 & 0.244 \\
$m_{4}$ & 0.116 & 0.375 & 0.125 & 0.384 \\
\hline
\end{tabular}

Table 14: The Transition Matrix for $m$ : Age 71-80

\begin{tabular}{c|c|c|c|c}
\hline$m^{\prime}=$ & $m_{1}$ & $m_{2}$ & $m_{3}$ & $m_{4}$ \\
\hline \hline$m_{1}$ & 0.694 & 0.254 & 0.026 & 0.027 \\
$m_{2}$ & 0.327 & 0.547 & 0.067 & 0.059 \\
$m_{3}$ & 0.195 & 0.544 & 0.105 & 0.156 \\
$m_{4}$ & 0.170 & 0.458 & 0.127 & 0.245 \\
\hline
\end{tabular}

Since the MEPS dataset also contains information on whether the individual survives to the next year, I can simply compute the corresponding conditional survival probabilities for each type of agent directly from the panel data. The computed conditional survival probabilities are reported in Table 4.

\subsection{Sensitivity Analysis}

In the benchmark model, I set the risk aversion parameter $\sigma$ to 2 following the tradition in the macro literature. To understand whether the main finding of the paper is sensitive to the value of the risk aversion parameter, now I explore several other values for $\sigma$ ranging from 1.5 to 4 as robustness checks. For each value of $\sigma$, I redo the computational experiment to quantify the impact of the correlation between health expenses and survival probabilities on the demand for health insurance. The results are reported in Table 16. As can be seen, the main finding of the paper remains true as the value of $\sigma$ varies. The correlation between health expenses and survival probabilities can still significantly reduce the demand for health insurance even when the value of $\sigma$ is set to as high as 4 . 
Table 15: The Transition Matrix for $m$ : Age 81-90

\begin{tabular}{c|c|c|c|c}
\hline$m^{\prime}=$ & $m_{1}$ & $m_{2}$ & $m_{3}$ & $m_{4}$ \\
\hline \hline$m_{1}$ & 0.667 & 0.273 & 0.036 & 0.024 \\
$m_{2}$ & 0.324 & 0.508 & 0.082 & 0.085 \\
$m_{3}$ & 0.187 & 0.527 & 0.173 & 0.113 \\
$m_{4}$ & 0.154 & 0.463 & 0.188 & 0.195 \\
\hline
\end{tabular}

Table 16: Risk Aversion $(\sigma)$ and the Health Coinsurance Rates (I)

\begin{tabular}{lcccccc}
\hline \multicolumn{1}{c}{$\epsilon_{1}$} & $\epsilon_{2}$ & $\epsilon_{3}$ & $\epsilon_{4}$ & $\epsilon_{5}$ & Average \\
\hline \hline$\sigma=1.5$ & & & & & & \\
\hline Benchmark & $0 \%$ & $66.7 \%$ & $79.5 \%$ & $61.5 \%$ & $10.3 \%$ & $59.5 \%$ \\
No correlation & $0 \%$ & $100 \%$ & $100 \%$ & $100 \%$ & $100 \%$ & $91.1 \%$ \\
\hline \hline$\sigma=2.0$ & & & & & & \\
\hline Benchmark & $0 \%$ & $87.2 \%$ & $79.5 \%$ & $61.5 \%$ & $30.8 \%$ & $66.3 \%$ \\
No correlation & $0 \%$ & $100 \%$ & $100 \%$ & $100 \%$ & $100 \%$ & $91.1 \%$ \\
\hline \hline$\sigma=3.0$ & & & & & & \\
\hline Benchmark & $94.7 \%$ & $89.5 \%$ & $84.2 \%$ & $68.4 \%$ & $31.6 \%$ & $78.7 \%$ \\
No correlation & $100 \%$ & $100 \%$ & $100 \%$ & $100 \%$ & $100 \%$ & $100 \%$ \\
\hline \hline$\sigma=4.0$ & & & & & & \\
\hline Benchmark & $100 \%$ & $89.5 \%$ & $84.2 \%$ & $68.4 \%$ & $47.4 \%$ & $80.6 \%$ \\
No correlation & $100 \%$ & $100 \%$ & $100 \%$ & $100 \%$ & $100 \%$ & $100 \%$ \\
\hline \hline
\end{tabular}

